\title{
Influence of Height Adjustment for Vossloh 300 Fasteners on Gauge Expansion and Bumping Shoulder Stress
}

\author{
Yu-Tao LIUa, Cheng-Hui LI ${ }^{\text {b, }}{ }^{*}$ and Ying-Jie ZHANG \\ ${ }^{1}$ MOE Key Laboratory of High-speed Railway Engineering, Chengdu, 610031, China \\ 2Liaoning Provincial Traffic Planning \& design Institute, Shenyang, 110000, China \\ a794417391@qq.com, bchli163chli@163.com, c807250462@qq.com
}

Keywords: Ballastless track, Fastener height adjustment, Vossloh300, Gauge expansion.

\begin{abstract}
In order to analyze the impact of height adjustment for Vossloh300 fasteners on the rail lateral displacement and the stress of sleeper bumping shoulder, the paper construct the mechanic model and finite element model, the rail lateral displacement and the stress of the sleeper bumping shoulder were calculated in terms of different adjustment heights. The results show that under the same load, the rail lateral displacement increases with the increasing fastener height adjustment, but the increment is small. The expansion of the rail lateral displacement results in rail lateral bending while has little influence on rail torsion. In addition, under the load, maximum principle stress of the joint between sleeper bumping shoulder and rail ditch. With the increasing of the adjust height, maximum principle stress of the sleeper bumping shoulder decreases.
\end{abstract}

\section{Introduction}

With recent years of development, ballastless track is used widely in China [1]. There are inevitable problems in ballastless track just as construction error, subgrade settlement and the creep camber of bridge beam body. In order to solve these problems, track height adjustment is always needed and a small scale height adjustment of ballastless track relies on rail fasteners [2]. There are four types of fasteners used on ballastless track in China, just as WJ-7, WJ-8, Vossloh300 and SFC fastener. WJ-8 and Vossloh300 fastener are applied to the ballastless track with sleeper shoulders and the other two fasteners are applied to ballastless track without sleeper shoulder. The height adjustment range of Vossloh300 fastener is $-4 \sim+56 \mathrm{~mm}$ and the other three fasteners is about $0 \sim 30 \mathrm{~mm}$ [3].

When adjust height of the track using fastener, it need to embed adjustment plates under the rail (or modify the thickness of the rail pad) and embed adjustment plates under the steel plate. When only embed adjustment plates under the rail, rail is elevated while the steel plate location is immobile which will affect the tilt angle of the fastener clip and its stress [4].

For the fastener used on ballastless track without sleeper shoulders, embedding adjustment plates under the steel plate will elevate the steel plate. For WJ-7 fastener, because lateral force is sustained by friction of steel plates, the anchor bolts only provide the vertical pressing force. Then, the elevation of steel plates have little effect on the anchor bolts. For SFC fastener, its anchor bolts need to carry lateral load, the elevation of steel plates will increase the moment arm of the lateral load which may increases the stress of bolts.

For the fastener used on ballastless track with sleeper shoulders, embedding adjustment plates under the steel plate will elevate the rail relative to the sleeper shoulders which will affect the lateral loading position and sleeper shoulders' stress. In addition, the lower elasticity of plastic adjustment plates whose elasticity modulus is about $1 / 36$ of sleeper shoulders and 1/5 of gauge plates may have influence on the bending deformation and torsion deformation of rail and the enlargement of rail gauge. The enlargement of rail gauge will change the wheel/rail contact location which may affect the wheel/rail force. The overlarge enlargement of rail gauge may affect the traffic safety [5]. The changes of sleeper shoulders stress may destroy sleeper shoulders and then reduce the fastener maintain ability of rail lateral stability, the worst case may cause train derailment [6]. Hence, it is necessary to analyze the effect of height adjustment on enlargement of rail gauge and sleeper shoulder stress while related research is less now. Because the height adjustment range of 
Vossloh300 is the largest, the paper will take Vossloh300 fastener as example to analyze the effect of height adjustment on enlargement of rail gauge and sleeper shoulders stress.

\section{Fastener Structure and Height Adjustment Theory}

Vossloh300-1U fastener mainly consists of anchor bolts, clips, gauge plates, rail pad and adjustment plates, as shown in Figure 1. The fastener fix the rail on sleeper by anchor bolts and clips which only restrict the torsion and overturn of rail and barely sustain lateral force. Lateral force of rail is sustained by gauge plates and sleeper shoulders [7].

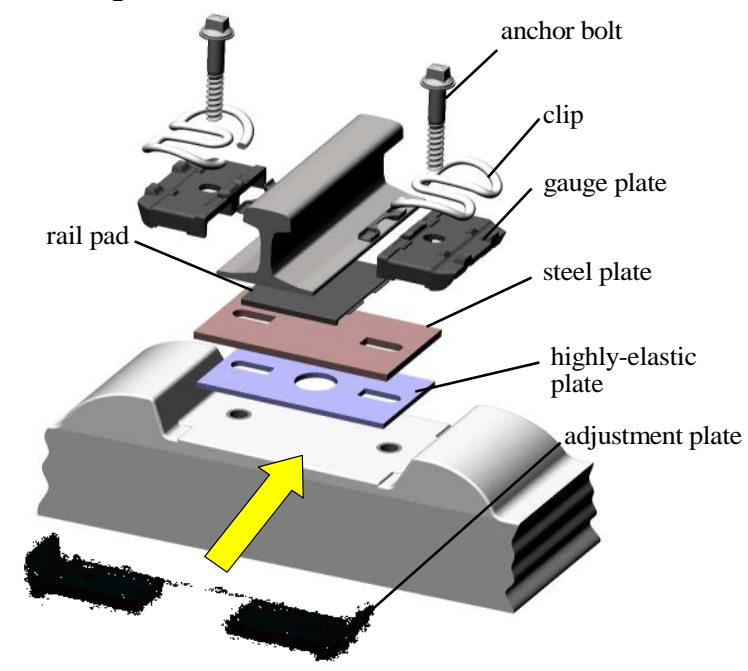

Figure 1 Composition of Vossloh300-1U

For Vossloh300-1U fastener, when adjust the height between $-4 \mathrm{~mm}$ and $+2 \mathrm{~mm}$, it only need to modify the thickness of rail pad. When adjust the height between $+3 \mathrm{~mm}$ and $+22 \mathrm{~mm}$, it should combine the modifying the thickness of rail pad and embedding plastic adjustment plates. When adjust the height between $+23 \mathrm{~mm}$ and $+56 \mathrm{~mm}$, it will embed the plastic adjustment plates and steel adjustment plates together [8]. The paper analyze five working conditions with adjust height is $0 \mathrm{~mm}, 12 \mathrm{~mm}, 20 \mathrm{~mm}, 38 \mathrm{~mm}$ and $56 \mathrm{~mm}$ and height adjustment mode is shown in Table 1.

Table 1 Height adjustment of five working conditions [9]

\begin{tabular}{|l|l|l|l|}
\hline $\begin{array}{l}\text { Height } \\
\text { adjustment[mm] }\end{array}$ & $\begin{array}{l}\text { Thickness } \\
\text { of rail } \\
\text { pad[mm] }\end{array}$ & $\begin{array}{l}\text { Plastic } \\
\text { adjustment } \\
\text { plates[mm] }\end{array}$ & Steel adjustment plates[mm] \\
\hline 0 & 6 & - & - \\
\hline 12 & 8 & $1 \times 10$ & - \\
\hline 20 & 6 & $2 \times 10$ & - \\
\hline 38 & 8 & $\begin{array}{l}1 \times 10 \\
+1 \times 6\end{array}$ & $1 \times 20$ \\
\hline 56 & 6 & $\begin{array}{l}1 \times 10 \\
+1 \times 6\end{array}$ & $2 \times 20$ \\
\hline
\end{tabular}

\section{Mechanical Model}

According to the loading features of Vossloh300-1U fastener, the mechanical model for analyzing height adjustment is established, as shown in Figure 2. The model is mainly simplified as follows:

(1) The anchor bolts only provide the vertical force while barely bear the lateral force, then anchor bolts are replaced by vertical loads for the convenience of analysis. 
(2) Because the sectional dimensions of clips are smaller than its length and it mainly bear the bending and torsion force, fastener clips are simplified to beams. In addition, ignoring the lateral force of clips and supposed that forelimbs of clips are closed to rail and hind limbs are closed to gauge plates under the press of anchor bolts.

(3) Supposed that rail pad and highly-elastic plate mainly provide the longitudinal resistance and vertical elastic, they are simplified to vertical springs with ignoring their lateral force.

(4) Steel plate is to spread the vertical load to highly-elastic plate, so ignore the interaction between steel plate and gauge plates.

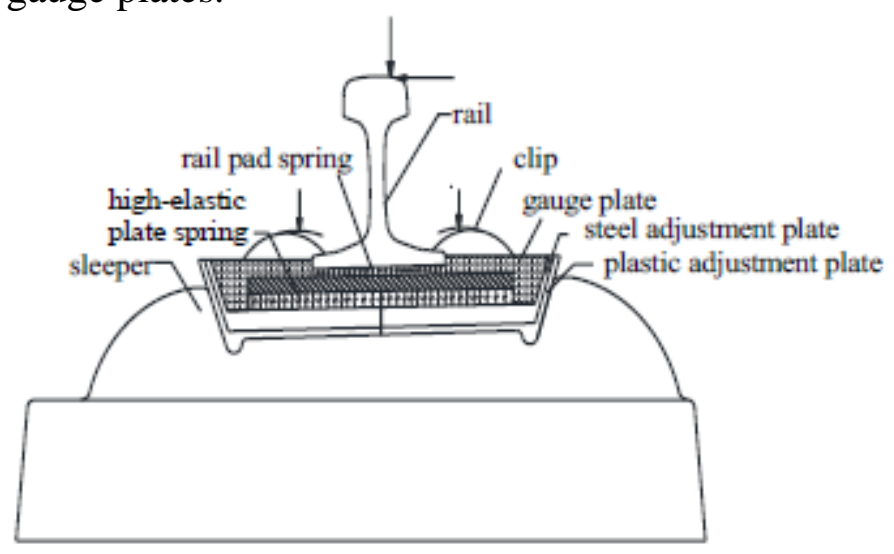

Figure 2 Mechanic model

\section{Finite Element Model}

Based on the above mechanical model, the paper use the finite element method to analyze the question by establishing a finite element model which include 14 spans about 9.27 mile rail, as shown in Figure 3. In the finite element model, gauge plates are connected to rail and adjustment plates (or sleeper) by contact element. When embedding multi-tier adjustment plates, construct the multi-tier adjustment plates with same material as one layer plate while different material adjustment are connected by contact element. Fastener clips forelimbs connect with rail by coupling the vertical degrees of freedom of related nodes. Fastener clips hind limbs connect with gauge plates by coupling the vertical degrees of freedom and lateral degrees of freedom of related nodes. Constraint all degrees of freedom of sleeper nodes at its bottom and side face.

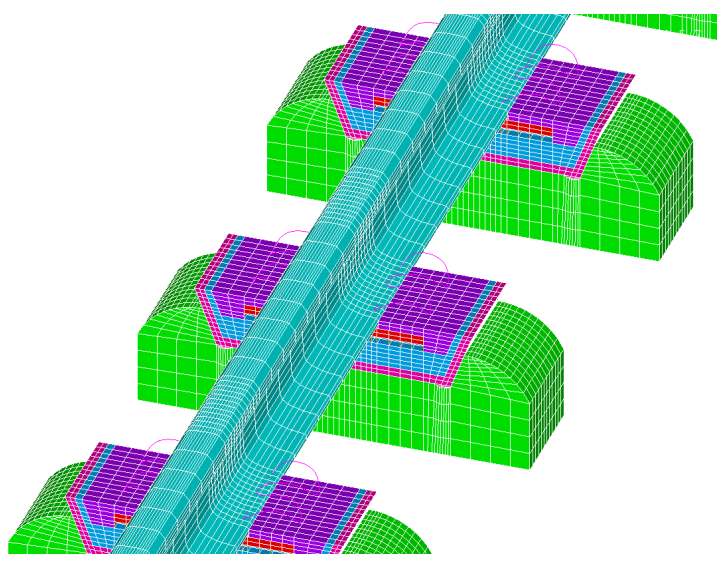

Figure 3 Finite element model

With reference to the literature [12], applied the loads to the rail elements in position of fastener. Vertical load is $140 \mathrm{KN}$ offset $10 \mathrm{~mm}$ from the center line of rail. Lateral load is $35 \mathrm{KN}$ offset $5 \mathrm{~mm}$ from top of rail, as shown in Figure 2. The torque of anchor bolt is $250 \mathrm{~N} \cdot \mathrm{m}$ which is convert to the $47 \mathrm{KN}$ vertical force between anchor bolt and fastener clip according the literature [3]. 
For consider the press of anchor bolts, calculation is taken by two steps: First, apply pre-loaded pressure on the scheduled nodes of fastener clips and calculate the deformation of the model. Second, constraint the node of load application and apply vertical and lateral load on rail ${ }^{[13]}$. The related material of model are shown in Table 2

Table 2 Related material parameters

\begin{tabular}{|l|l|l|l|l|l|}
\hline $\begin{array}{l}\text { elasticity } \\
\text { modulus of } \\
\text { gauge } \\
\text { plate } \\
{[\mathrm{GPa}]}\end{array}$ & $\begin{array}{l}\text { Rail pad } \\
\text { stiffness } \\
{[\mathrm{KN} / \mathrm{mm}]}\end{array}$ & $\begin{array}{l}\text { High-elastic } \\
\text { plate stiffness } \\
{[\mathrm{KN} / \mathrm{mm}]}\end{array}$ & $\begin{array}{l}\text { elasticity modulus } \\
\text { of steel } \\
\text { adjustment plate } \\
{[\mathrm{GPa}]}\end{array}$ & $\begin{array}{l}\text { elasticity modulus } \\
\text { of plastic } \\
\text { adjustment } \\
\text { plate }^{[11]}[\mathrm{GPa}]\end{array}$ & $\begin{array}{l}\text { elasticity } \\
\text { modulus of } \\
\text { fastener clip } \\
{[\mathrm{GPa}]}\end{array}$ \\
\hline 5 & 400 & 25 & 210 & 1.1 & 200 \\
\hline
\end{tabular}

\section{Influence of Height Adjustment on Rail Gauge Enlargement}

Under vertical and lateral load, rail occur the bending, overall inclination and torsion deformations. The law of rail gauge enlargement can be draw from the largest lateral displacement. Then abstract the largest lateral displacement under different adjustment height as shown in Figure 4.

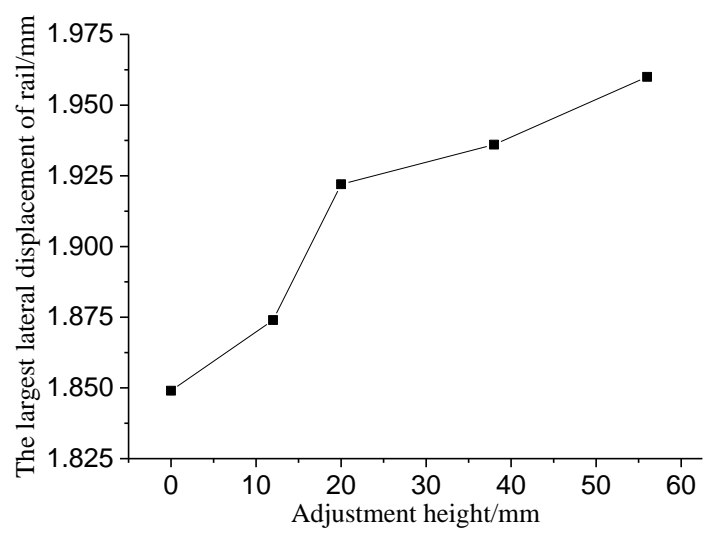

Figure 4 Lateral displacement of rail under different adjusted height

From the Figure 4, though the lateral displacement increase with adjustment height, the lateral displacement increase small. The largest lateral displacement is $1.849 \mathrm{~mm}$ when there are no height adjustment. The largest lateral displacement is $1.96 \mathrm{~mm}$ when adjustment height is $56 \mathrm{~mm}$. Literature [14-15] take lateral displacement of rail as the combination of lateral bending displacement and lateral torsion displacement. In order to distinguish the influence of adjustment height on lateral bending displacement and lateral torsion displacement, abstract the vertical centerlines of rail under five working conditions as shown in Figure 5. 


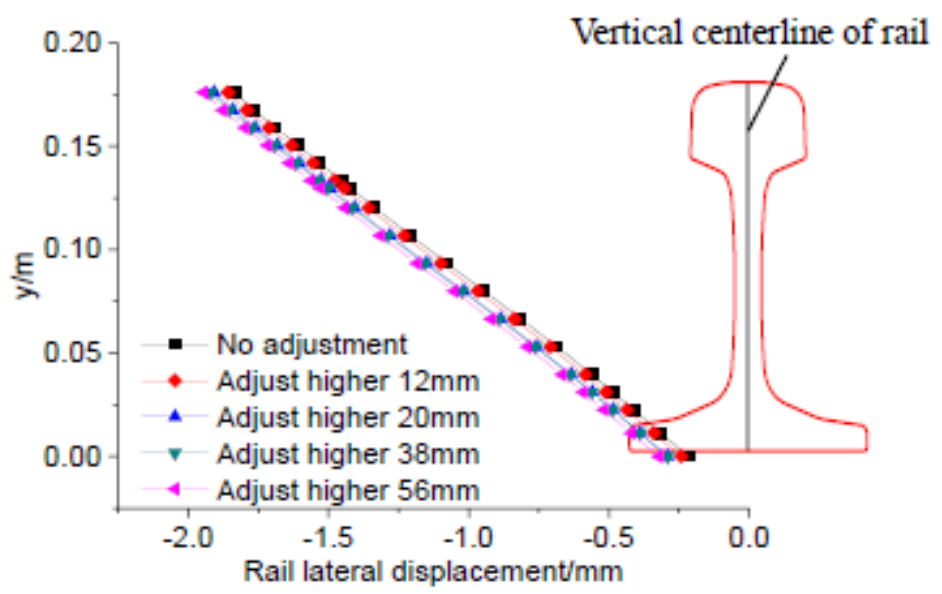

Figure 5 Position modification of the rail's vertical centerline

Before applied load, the vertical centerline of rail is a vertical line whose abscissa is zero. Under the loads, rail occur the bending, overall inclination and torsion deformation and the location of vertical centerline of rail has changed. From the Fig.5, the inclination angles of vertical centerlines are about 0.0092rad and it changes little under different adjustment heights. Hence, the torsion degrees of rail are similar under different under different adjustment heights. The increase of lateral displacement of rail is mainly due to the increase of lateral bending displacement. The lateral displacement caused by inclination and torsion of rail changes little.

\section{The Influence of Height Adjustment on Stress of Sleeper Shoulder}

For analyze the influence of height adjustment on stress of sleeper shoulder, abstract the first principal stress contour line of sleeper under the condition of no height adjustment, adjustment height $12 \mathrm{~mm}$ and adjustment height 56mm as shown in Figure 6-Figure 8.

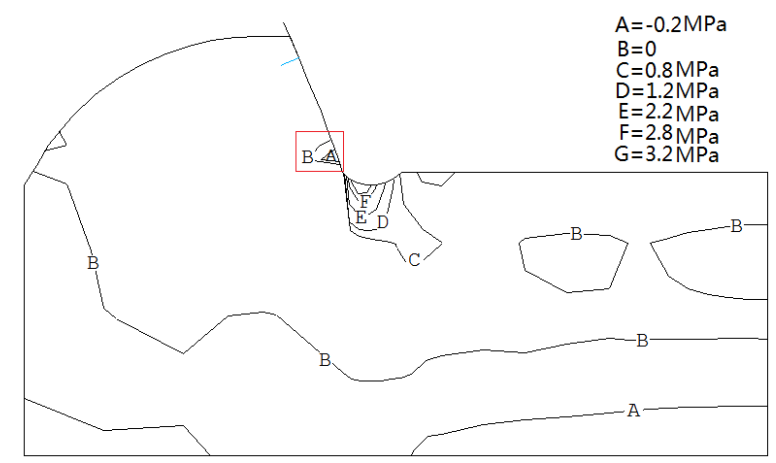

Figure 6 Equal stress curve of sleeper shoulder with no height adjustment

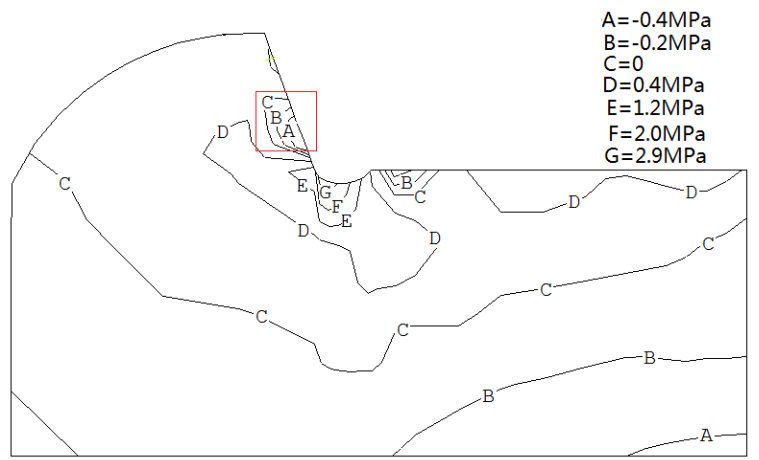

Figure 7 Equal stress curve of sleeper shoulder when adjust higher $12 \mathrm{~mm}$ 


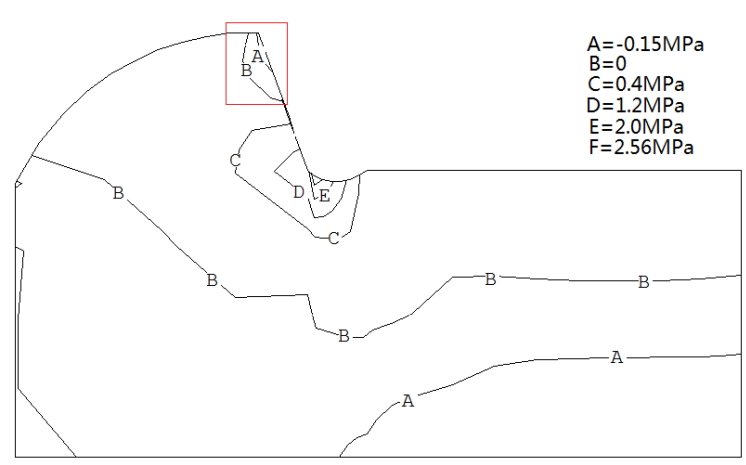

Figure 8 Equal stress curve of sleeper shoulder when adjust higher $56 \mathrm{~mm}$

As shown in Figure 6-Figure 8, the largest first principal stresses occur at the connection of sleeper shoulder and rail support slot. In addition, the largest first principal stress decrease with the increase of height adjustment. When there is on height adjustment, the largest first principal stress is $3.2 \mathrm{MPa}$. When the adjustment height is $56 \mathrm{~mm}$, the largest first principal stress is $0.64 \mathrm{MPa}$.

\section{Conclusion}

By above calculation it can be obtained that the influence of adjustment height on rail lateral displacement and sleeper shoulder stress can be stated by following two aspects:

1. Though the lateral displacement increase with adjustment height, the lateral displacement increase small. The increase of lateral displacement of rail is mainly due to the increase of lateral bending displacement. The lateral displacement caused by inclination and torsion of rail changes little.

2. Under the lateral and vertical load, the largest first principal stresses occur at connection of sleeper shoulder and rail support slot. In addition, the largest first principal stress decrease with the increase of adjustment height.

Because the simplifications in the calculation, there are deviations between the calculated results and realities of situation, it should be revised by field test.

\section{References}

[1] Li Chenghui. Track[M]. Chengdu: Southwest Jiaotong Un- versity Publishing House, 2005.

[2] Diego,S. Experimental validation of an adjustable railway fastening for slab track[J], Journal of Testing and Evaluation,2010,38(5):598-608.

[3] Wang Qichang. Rail Fastening of Ballastless Track [M].Chengdu: Southwest Jiaotong University Publishing House, 2006.

[4] Zhu Shengyang, Cai Chengbiao. Dynamic Analysis of Rail Fastening Clip in High-speed Railway[J]. Engineering Mechanics,2013,30,(6):254 -258

[5] Lian Songliang, Liu Libo, Joe. Kalousek. Theoretical Analysis of Gauge Widening under Load[J]. Chinese Railways,2000( 22):30-35.

[6] Zhao Guotang. High Speed Railway Ballastless Track Stru- cture[M]. Beijing: China Railway Publishing House, 2006.

[7] Vossloh rail fastening corporation. Vossloh Rail Fastening system 300-1U for Slab Track [CP].

[8] Railways Project Management Center. Passenger Dedicated Railway Fastener System Installation Manual[M]. Beijing: China Railway Publishing House, 2009

[9] Provisional technical conditions of passenger dedicated line[S].Beijing: China Railway Publishing House, 2006. 
[10] Wang Ting. Performance Study of Glass Fiber Reinforced Polyamide[J]. Technology \& Development of Chemical Industry, 2010(2):18-20.

[11] Dai Jiali, Li Zhihui. Relationship of Mechanical Properties of HDPE and Toughened HDPE with Test Conditions[J]. China Plastics Industry,2006,34(11): $42-45$.

[12] Zhang Yingjie. Effect Analysis of Fastening System Vertical Adjustment of Ballastless Track[D]. Southwest Jiaotong University, 2013.

[13] Wang Xinmin. ANSYS Structural Engineering numerical Analysis [M]. Beijing: China Communications Press, 2007.

[14] Zhang Yongxing,Lian Songliang. Analysis of Lateral displacement of rail while considering the twist of rail[J]. Journal of Shanghai Tiedao University (NaturalScience Edition),1997,18(3):1823.

[15]Liu Yongjun. Elementary Research on the Overturning Stiffness of Track Under Load[J]. Journal of Railway Engineering Society,2002(4) : 26-27. 